\title{
Ansätze eines Vergleiches: Gemeinsame Wurzeln und verschiedene Wege. Kommentar zu den Vorträgen in der Sektion „Religiöse Anliegen des Mönchtums; Entstehungsbedingungen des Mönchtums“
}

Ein Vergleich der frühen Stadien des Mönchtums im östlichen Teil des spätrömischen Reiches, im westeuropäischen Raum des Mittelalters sowie in der Kiever und Moskauer Rus' legt den Schluss nahe, dass im Gegenteil zum westlichen Klosterwesen das mittelalterliche russische Mönchtum die zwei wichtigsten mit sich konkurrierenden Grundformen des Asketentums der Spätantike - das Eremitentum, verkörpert durch das Leben des heiligen Antonius in der ägyptischen Wüste (eremos) einerseits, und das Koinobitentum, veranschaulicht durch die Regel des Pachomius, andererseits übernommen und über Jahrhunderte hinweg weiterentwickelt hat.

Die Anfänge des ersten russischen monastischen Hauses, des Kiever Höhlenklosters, das im 11. Jahrhundert außerhalb der Stadtgrenze von Kiew entstand, zeigen sowohl eremitische und koinobitische Tendenzen auf. Wie sein ägyptischer Vorläufer gleichen Namens strebte der heilige Antonij, einer der beiden Gründer des Kiever Höhlenklosters, der eine Zeit seines Lebens in einer Höhle außerhalb der Hauptstadt des ersten Russischen Reiches verbrachte, nach einem Leben in der Einsamkeit, das ihn durch Kontemplation und strenge asketische Selbstzucht Gott näherbringen würde. Antonijs Nachfolger, Feodosij, bemühte sich andererseits um die Organisation eines kommunitären Mönchslebens im Kiever Höhlenkloster nach dem Muster der byzantinischen Mönchsregel des Theodor von Studion, die sich ihrerseits von den frühen koinobitischen Experimenten in der ägyptischen Wüste und in Palästina ableiten lässt.

Zwar fand das asketische Element des christlichen Urmönchtums, das die charismatische spirituelle Leistung des Einzelmönches hervorhebt, durch Figuren wie Kassian und Martin von Tours im Frühmittelalter auch seinen Weg nach Gallien. Aber die Entwicklung des westlichen Mönchtums wurde entscheidend vom kommunitären Verständnis der monastischen Existenz geprägt, das in der Benediktsregel und in zahlreichen späteren Ordensregeln Ausdruck fand. Gründe dafür mögen nach Rudolf Lorenz der augustinische Einfluss sein, der die spirituelle Stärkung der Gemeinschaft durch Arbeit und die Ordnungsschaffung durch einen Abt befürwortete, darüber hinaus die Tendenz im Westen, das geistliche Streben des Mönches innerhalb einer Gemeinschaftsstruktur zu verwirklichen, die zudem, wie Philip Rousseau festgestellt hat, Autorität eher legalistisch als charismatisch auffasste. Die Kontrolle des individuellen Mönchslebens erschien als ein Hauptanliegen der westlichen Kirche, die 
auch weniger strukturierte religiöse Lebensformen, wie das Anachoretentum oder das Beguinentum, zu überwachen suchte. In diesem Zusammenhang ist es nicht verwunderlich, dass Reformversuche des mittelalterlichen westlichen Mönchtums, veranschaulicht durch die Bildung der Kartäuser-, Zisterzienser- oder der Bettelorden, nur innerhalb der existierenden Gemeinschaftsstruktur des Mönchtums ihre Realisierung erfuhren.

Im Vergleich zur Situation im mittelalterlichen Westen hielt die Entwicklung des russischen Mönchtums die Spannung zwischen den frühchristlichen Idealen des Eremitentums und des Koinobitentums in der Kiever und Moskauer Zeit aufrecht. Zwar folgten, wie im Westen, die meisten russischen Klöster einem Gemeinschaftsmodell und entwickelten sich, besonders seit dem Sieg der „Eigennützigen“ über die „Uneigennützigen“ im frühen 16. Jahrhundert, zu wohlorganisierten Wirtschaftsunternehmen, die eine enge Zusammenarbeit zwischen Kirche und Staat befürworteten. Aber die fortdauernde Koexistenz mit idiorrythmischen Häusern zeigt, dass das Bestreben der frühchristlichen Asketen wie des heiligen Antonius, von der Welt vollkommen unabhängig zu sein und jeglichen Besitz und gesellschaftliche Beziehungen zu meiden, in der russischen Mönchsauffassung nie ausstarb. Frühe Anzeichen der fortwährenden russischen Neigung zum selbstlosen, charismatischen Mönchsideal sind in der Klosterkolonisationsbewegung des 14. und 15. Jahrhunderts zu beobachten, als russische Asketen mit oder ohne vorheriges Noviziat ein Leben der Selbstentsagung weitab von Städten anstrebten und in der russischen Waldwüste die Härte der Bedingungen der ägyptischen Wüste nachzuvollziehen suchten. Obwohl die von russischen Mönchsheiligen wie Sergij Radonežskij und Kirill Belozerskij geschaffenen Einsiedeleien sich mit der Zeit in Einödklöster verwandelten, die später oft zum Koinobitentum übergingen, wurde die Gefahr der Verweltlichung der russischen Klöster, von der Igor Smolitsch spricht, immer wieder von neuen Asketen überwunden, die im 16. und 17. Jahrhundert in der Wildnis des russischen Nordens die russische Thebais schufen. Im Gegensatz zum Westen wurde der Reformgedanke des Mönchtums in der Moskauer Rus’ nicht von neuen Orden wie den Zisterziensern, welche die Randgebiete des westkirchlichen Europa besiedelten, getragen, sondern vielmehr von individuellen Asketen, die nur spärlichen Kontakt mit Kirchenbehörden aufnahmen. Während die bebaute und erschlossene Landschaft Westeuropas im späten Mittelalter die Möglichkeit eines eremos geradezu ausschloss, schuf das ständige Vordringen des Moskauer Herrschaftsgebiets in wenig besiedelte, vom Christentum unberührte Gebiete im Norden und Osten die Bedingungen für neue asketische Lebensräume, die ständig Wandermönche anzogen, die das Ideal der individuellen charismatischen Askese im russischen Mönchtum aufrechterhielten. 


\section{Kommentar zu Andreas Müllers Vortrag: „Das spätantike Mönchtum als transkulturelles Phänomen.“}

In seiner Untersuchung des spätantiken Mönchtums zeigt Andreas Müller, dass die Mönchsbewegung des 5. und 6. Jahrhunderts sich nicht auf einen regionalen Kontext beschränkte, was durch die hohe Mobilität von Mönchen und Nonnen begründet ist. Das Phänomen der reisenden Mönche schuf eine internationale Klosterkultur in den geographischen Räumen des Römischen Reiches, die Mönche aus verschiedenen Sprach- und Kulturgebieten zusammenbrachte. Diese Interkulturalität lässt sich sowohl in Heiligenviten und Pilgerberichten als auch in Quellensammlungen wie der Historia Lausiaca bestätigen.

Die Mobilität des spätantiken Mönchtums und ihr kommunitärer Aspekt sind insofern verwunderlich, da der ursprüngliche Sinn des Mönchtums, Kontakt mit der Welt $\mathrm{zu}$ vermeiden (monachos bedeutet Alleinsein) mit der Vorstellung der Interaktion von Mönchen aus verschiedenen Sprach- und Kulturgebieten nicht zusammenpasst. Auf der anderen Seite ist der weltfliehende Aspekt des Mönchtums eng mit dem Motiv des Wanderns, des Verlassens von vertrauten Sozialstrukturen, und daher der Mobilität verbunden. Die noch im 5. und 6. Jahrhundert weithin bestehende Infrastruktur des Römischen Reiches, das Straßennetz und auch die Schifffahrt, machte es Anhängern des Mönchsgedankens möglich, ferne Klosterzentren wie das Katharinenkloster auf dem Berg Sinai entweder zu besuchen oder zum Zielort ihres Klostereintritts zu machen. Das generelle Streben des römischen Staates, die regionalen und kulturellen Differenzen innerhalb seiner Grenzen zu überwinden, kam der Schaffung eines spätantiken transregionalen und transkulturellen Mönchtums entgegen. Dieses Ideal bestand in der byzantinischen Periode weiter, als auch russische Mönche Klöster in Griechenland, Ägypten und im Heiligen Land weiter besuchten und dort, wie auch Elena Romanenko in ihrem Vortrag berichtet, Kenntnisse über Klosterregeln und Mönchsideale erwarben. Die Situation veränderte sich nach dem Fall Konstantinopels in 1453, als Mönche aus orthodoxen Klöstern im ehemaligen byzantinischen Reichsgebiet ins Moskauer Reich reisten, um den Zaren um ökonomische Hilfe zu bitten, russische Mönche ihrerseits aber ihren Blick auf den russischen Norden richteten, der die Möglichkeit der Schaffung einer eigenen russischen Thebais bot. Wie ihre spätrömischen Vorgänger besuchten russische Mönche, sowohl individuelle Asketen als auch koinobitisch lebende Mönche, einander und tauschten vermutlich Gedanken aus. Ein gutes Beispiel dafür ist die Interaktion der Heiligen Sergij Nuromskij und Pavel Obnorskij. Die unbesiedelten Gebiete im russischen Norden und Osten des Moskauer Reiches spornten die Mönche zur Mobilität an. In diesem Kontext ist allerdings anzumerken, dass das Zarenreich im 16. und 17. Jahrhundert kein ausgeprägtes Konzept von individuellen Regionen besaß und dass die nichtrussischen Kulturen auf seinem Boden (wie Gebiete, die von Tataren 
oder finno-ugrischen Stämmen bewohnt waren) entweder noch gar nicht oder nicht tief christianisiert waren und daher keine eigene Konzeptionen des Mönchtums aufzuweisen hatten.

\section{Kommentar zum Vortrag von Elena Romanenko: „Gründer russischer Klöster: sozialer und kultureller Status.“}

Dieser Vortrag bietet eine statistische Untersuchung des sozialen Hintergrunds und des Bildungsstandes der Klostergründer des russischen Mittelalters, die uns in ein soweit noch wenig erforschtes Gebiet führt. Aufgrund einer Auswertung der Minäen des Monats Mai teilt Elena Romanenko ihre Ergebnisse in zwei Perioden, die des Aufstiegs des Moskauer Reiches, d.h. das 14. und 15. Jahrhundert, und die seiner späteren Entfaltung, d. h. das 16. und 17. Jahrhundert, ein Zeitraum, der ab der Mitte des 16. Jahrhunderts mit dem Moskauer Zarentum zusammenfällt. Die Angaben des sozialen Hintergrundes der russischen Klostergründer in den Minäen lassen darauf schließen, dass in der frühen Phase des russischen Mönchtums der russische Adel eine große Rolle in der Errichtung von neuen Klöstern spielte. Wie Romanenko zeigt, ging dieses Interesse des Adels am Mönchtum im 17. Jahrhundert zurück, Bauern und Städter übernahmen seine Rolle. Interessanterweise blieb das relativ geringe Interesse von Angehörigen der geistlichen Hierarchie an Klostergründungen unverändert. Was die Bildung der Klostergründer angeht, scheinen die Daten dafür zu sprechen, dass die Klostergründer der zweiten Periode eine geringere Erziehung besaßen als die der ersten Gruppe, was sich möglicherweise durch den niedrigeren Sozialstatus der Mitglieder der zweiten Gruppe erklären lässt. Die Ergebnisse von Romanenkos Studie unterstützen die Annahme, der anscheinend auch die Autorin der Studie anhängt, dass das 14. und 15. Jahrhundert das goldene Zeitalter des russischen Mönchtums war - die Zeit, als hervorragende russische Mönchsfiguren wie Kirill Belozerskij, Nikon Radonežskij, Stefan Permskij, Efrosin von Pskov, Iosif Volockij und Nil Sorskij bedeutende Klöster gründeten und Mönchsregeln schufen. Romanenkos Studie hebt besonders hervor, dass die Klostergründer dieser Periode einen weiten kulturellen Horizont hatten, da sie sich auf Pilgerfahrten nicht nur innerhalb Russlands begaben, sondern auch in andere orthodoxe Gebiete, so in die byzantinische Hauptstadt, zum Berg Athos, nach Palästina und sogar nach Süditalien. Der hohe Bildungsstand der zumeist adeligen Klostergründer dieses Zeitabschnitts scheint daher für die Entwicklung des russischen Mönchsideals und die literarische Kreativität innerhalb der russischen Klöster des 14. und 15. Jahrhunderts verantwortlich gewesen zu sein.

Der These dieser Untersuchung, dass die aristokratischen Klöster des 14. und 15. Jahrhunderts im Vergleich zu ihren spätmittelalterlichen Nachfolgern in Bezug auf 
ihr theologisches und literarisches Schaffen fruchtbarer waren, könnte man entgegenstellen, dass Historiker die intellektuelle Neugier und die literarische Kreativität der späteren Mönche noch nicht genügend erforscht haben. Im 17. Jahrhundert war es Mönchen aus dem Bauernstand durchaus möglich, einen hohen Bildungsgrad zu erreichen, wie die Beispiele des Patriarchen Nikon und des Erzbischofs Nektarij von Tobol'sk beweisen. Zwar reisten die Klostergründer des späteren Moskauer Reiches nicht ins Ausland, aber viele begaben sich als Wandermönche auf einen weiten, beschwerlichen Weg in die abgelegenen Wälder und in die Eiswüste des russischen Nordens auf der Suche nach einem asketischen Lebensstil. Die Viten vieler Mönchsheiligen, wie z. B. des Sergij Nuromskij und Pavel Obnorskij, sprechen davon, dass das strikte Mönchsideal dieser Männer vom Austausch ihrer Ideen geprägt war und getragen wurde. Die Inventare der Klöster dieser Zeit verweisen auf ein generelles Streben der Bruderschaften, Bücher mit geistlichem Inhalt, oft auch byzantinischer Herkunft, zu sammeln, und, wie man annehmen sollte, zu lesen. Was das literarische Schaffen der späteren Mönche betrifft, sollte man nicht vergessen, das die Viten der Heiligen des russischen Nordens - viele zur Zeit noch nicht publiziert - zum größten Teil in Klöstern dieser Region erst im 16. und 17. Jahrhundert verfasst wurden. Man denke zum Beispiel an bekannte Hagiographen wie Filofej Pirogov und Sergij Šelonskij und an die große Anzahl von anonymen Verfassern von Viten. Wenn man dazu noch die Unmengen von Redaktionen von Heiligenviten und liturgischen Werken, die von Mönchen im 17. Jahrhundert verfasst wurden, rechnet, kann man wohl kaum von einem Abstieg der klösterlichen Kreativität in der Moskauer Zeit sprechen.

\section{Kommentar zu Vasilij Ivanovs Vortrag: „Desperatio facit monachum". Mönchtum als Weg zur Reformation.“}

In seinem Vortrag argumentiert Vasilij Ivanov, dass man die Reformation als eine Fortsetzung des mittelalterlichen Begriffs der Kirchenreform, die zur Gründung der Bettelorden im 13. Jahrhundert und zur Spaltung der Franziskaner in Konventuale und Spirituelle im folgenden Jahrhundert führte, auffassen sollte. Die Spannung zwischen dem Papsttum und den reformorientierten Mönchsgruppen im späten Mittelalter warf die allgemeine Frage der Rolle des Mönchtums in der christlichen Weltauffassung auf, eine Frage, die Ivanov mit der ideologischen Krise des Spätmittelalters verbindet. Laut Ivanov suchten einige Reformatoren im Mönchtum eine geistliche Alternative, eine Möglichkeit, das bestehende weltanschauliche System zu reformieren und nicht zu zerstören, bevor sie zur radikalen Ablehnung des Mönchtums schritten. Die Ablehnung des Mönchtums erschien als ein Hauptpunkt, der die Anhänger der traditionellen Kirche von den Reformatoren unterschied. 
Wie Ivanov selbst zugibt, ist es schwierig, die persönliche Einstellung der Reformatoren zum Mönchtum von ihrer allgemeinen Einschätzung der Reformierbarkeit dieser Institution $\mathrm{zu}$ unterscheiden. Letzten Endes waren Fragen, die der weltanschaulichen Krise am Ausgang des Mittelalters entsprangen, entscheidender. Solche Fragen hingen mit dem allgemeinen menschlichen Zugang zu Gott, mit der Rolle der göttlichen Gnade im christlichen Erlösungsprozess und mit Zweifeln an der Bedeutung von guten Taten zusammen. All diese Probleme waren in der Institution des Mönchtums verkörpert, da die Mönche traditionell als ideale Fürbitter galten, die durch ihre Bittgebete die Erlösung einfacher Menschen beeinflussen konnten, also einen näheren Zugang zu Gott als der Durchschnittsmensch inne hatten.

Ein Vergleich mit Russland ist in Hinsicht auf dieses Thema schwierig, da die Orthodoxie keine Mönchsorden kennt. Wenn man aber die westliche Reformationsbewegung mit dem Streit um die Reform der Kirchenrituale zwischen den Anhängern des Patriarchen Nikon und den Altgläubigen, der in der Mitte des 17. Jahrhunderts ausbrach, vergleicht, heben sich einige Unterschiede heraus. Beide Seiten sahen sich als Reformer: die Nikonianer waren bestrebt, die russischen Kirchenrituale von Neuerungen der Moskauer Zeit zu säubern, und orientierten sich dabei an den gültigen griechischen Normen. Die Altgläubigen hingen kämpften aus Furcht vor dem Verlust der russischen Tradition, die das Moskauer Reich nach dem Fall Konstantinopels 1453 an die Türken als das Land des wahren orthodoxen Glaubens ansah, gegen den griechischen Einfluss im eigenen Kirchenleben. Im Fall der Altgläubigen hing die Frage der Erlösung vom korrekten liturgischen Ritual ab, das den Zugang jedes Christen zu Gott bestimmte. Der Reformgedanke der Altgläubigen ist daher rückblickend, traditionell und konservativ eingestellt im Vergleich zu dem der Reformatoren, die eine neue Beziehung zwischen Gott, Kirche und Gläubigen im Auge hatten. Von dieser Sicht aus ist es nicht verwunderlich, dass nicht nur das große Kloster auf Solovki im Weißmeer auf dem alten Ritus beharrte, sondern, wie Georg Michels in seiner Monographie At War with the Church nachgewiesen hat, sich auch eine Anzahl von kleineren Klöstern der Altgläubigenbewegung anschloss. 